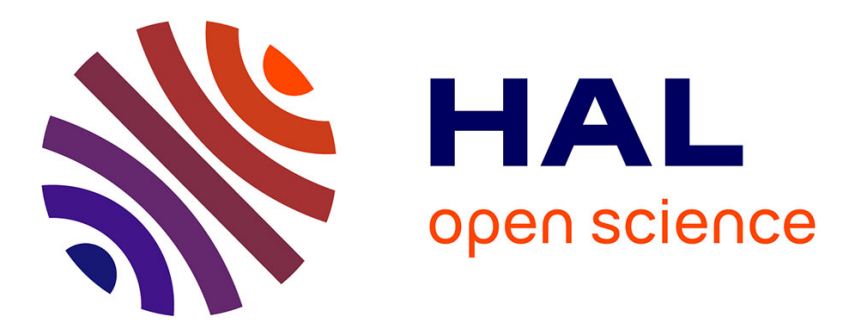

\title{
Telemedicine framework using case-based reasoning with evidences
}

\author{
Alsane Sene, Bernard Kamsu-Foguem, Pierre Rumeau
}

\section{To cite this version:}

Alsane Sene, Bernard Kamsu-Foguem, Pierre Rumeau. Telemedicine framework using case-based reasoning with evidences. Computer Methods and Programs in Biomedicine, 2015, vol. $121\left(\mathrm{n}^{\circ} 1\right)$, pp. 21-35. 10.1016/j.cmpb.2015.04.012 . hal-01256707

\section{HAL Id: hal-01256707 https://hal.science/hal-01256707}

Submitted on 15 Jan 2016

HAL is a multi-disciplinary open access archive for the deposit and dissemination of scientific research documents, whether they are published or not. The documents may come from teaching and research institutions in France or abroad, or from public or private research centers.
L'archive ouverte pluridisciplinaire HAL, est destinée au dépôt et à la diffusion de documents scientifiques de niveau recherche, publiés ou non, émanant des établissements d'enseignement et de recherche français ou étrangers, des laboratoires publics ou privés. 


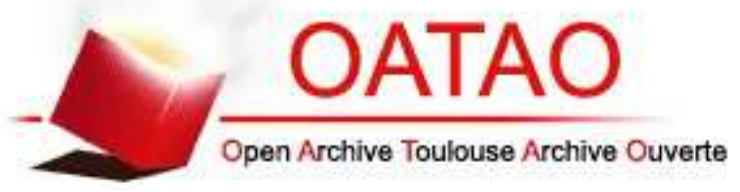

\section{Open Archive Toulouse Archive Ouverte (OATAO)}

OATAO is an open access repository that collects the work of Toulouse researchers and makes it freely available over the web where possible.

This is an author-deposited version published in: http://oatao.univ-toulouse.fr/ Eprints ID: 13953

To link to this article: DOI: $10.1016 / \mathrm{j} . \mathrm{cmpb} .2015 .04 .012$

http://www.sciencedirect.com/science/article/pii/S0169260715001108

\section{To cite this version:}

Sene, Alsane and Kamsu-Foguem, Bernard and Rumeau, Pierre Telemedicine framework using case-based reasoning with evidences. (2015) Computer Methods and Programs in Biomedicine, vol. $121\left(\mathrm{n}^{\circ} 1\right)$. pp. 21-35. ISSN $\underline{0169-2607}$ 


\title{
Telemedicine framework using case-based reasoning with evidences
}

\author{
A. Sene $e^{a, b}$, B. Kamsu-Foguem ${ }^{a, *}$, P. Rumeau ${ }^{b}$ \\ a Laboratoire Génie de Production (LGP), EA 1905, ENIT-INPT, Université de Toulouse, 47 avenue d'Azereix, BP 1629, \\ 65016 Tarbes Cedex, France \\ b Laboratoire de Gérontechnologie La Grave, CHU Toulouse/Gérontopôle/UMR 1027 Inserm-Université Toulouse 3, \\ Hôpital La Grave, Place Lange, TSA 60033, 31059 Toulouse Cedex 9, France
}

Keywords:

Telemedicine

Case-based reasoning

Evidence sources

Medical taxonomy

Oncology

\begin{abstract}
A B S T R A C T
Telemedicine is the medical practice of information exchanged from one location to another through electronic communications to improve the delivery of health care services. This research article describes a telemedicine framework with knowledge engineering using taxonomic reasoning of ontology modeling and semantic similarity. In addition to being a precious support in the procedure of medical decision-making, this framework can be used to strengthen significant collaborations and traceability that are important for the development of official deployment of telemedicine applications. Adequate mechanisms for information management with traceability of the reasoning process are also essential in the fields of epidemiology and public health. In this paper we enrich the case-based reasoning process by taking into account former evidence-based knowledge. We use the regular four steps approach and implement an additional (iii) step: (i) establish diagnosis, (ii) retrieve treatment, (iii) apply evidence, (iv) adaptation, (v) retain. Each step is performed using tools from knowledge engineering and information processing (natural language processing, ontology, indexation, algorithm, etc.). The case representation is done by the taxonomy component of a medical ontology model. The proposed approach is illustrated with an example from the oncology domain. Medical ontology allows a good and efficient modeling of the patient and his treatment. We are pointing up the role of evidences and specialist's opinions in effectiveness and safety of care.
\end{abstract}

\section{Introduction}

Telemedicine is a remote medical practice using telecommunication and information technologies. It is an efficient tool for collaboration between physicians but it also offers many others benefits (e.g. cost savings, improved care, improved access and real-time responses). Like any medical practice, telemedicine aimed at establishing a diagnosis, providing a preventive or post-therapeutic medical monitoring, performing medical acts, prescribing drugs and services.

The large amount of health knowledge available to the medical personnel is hardly embraced. Medical information is doubling every 5 years [1] and $81 \%$ of the physicians spend

\footnotetext{
* Corresponding author. Tel.: +336243023 37/6145561 64; fax: +33 562442708 .

E-mail addresses: senealou12@hotmail.fr (A. Sene), Bernard.Kamsu-Foguem@enit.fr (B. Kamsu-Foguem), rumeau.p@chu-toulouse.fr (P. Rumeau).
} 
less than $5 \mathrm{~h}$ per month reading medical journals. Only 20\% of the knowledge used by clinicians relies on evidence-based resources. In the United States of America (USA), there are an estimated 1.5 million prescriptions and medication errors amounting for an extra cost of close to $50 \%$. The analysis of structured medical data could help retrieve former similar cases and help in choosing the best diagnosis and treatment strategy, as well as ease the extraction of epidemiological information [2].

Telemedicine is a new medical approach contributing to the improvement of health care access and provision (e.g. penitentiary institutions, nursing homes, mountainous regions or less-favored areas). It can provide additional healthcare opportunities particularly in the fields of aviation, space and maritime transport; where proper remote diagnosis and treatment can avoid costly medical evacuation services (MEDEVAC).

Telemedicine is scarcely written in law, but national governments and healthcare authorities influence the organization of health care services at a distance, like in France where we will test our research method. The French Law has defined five acts of telemedicine in decree $n^{\circ} 2010-1229$ (October 19, 2010) [3]:

- Teleconsultation: a physician performs a remote consultation to a patient who can be assisted by health professional.

- Teleexpertise: a physician solicits remotely other physicians to discuss and treat a case.

- Medical telemonitoring: a caregiver observes and interprets medical signs of patient. This can be done either in the manual or automatic mode.

- Medical teleassistance: a physician assists remotely another medical professional to perform a medical act.

- Medical coordination of emergency.

Telemedicine benefits from a large bibliography but practical challenges remain: organizing the management of the knowledge wealth, improving security engineering and risk management in the context of a continuous improvement of healthcare services. In this context, information modeling can be traced according to medical patterns through structured data that are linked to practices via telecommunication technologies.

Thereafter, we propose to enrich the case-based reasoning (CBR) process with a conceptual information system architecture that seeks to reflect both the conventional medical reasoning and the CBR. This architecture is based on conventional medicine step by step process. The first four stages reflect the medical consultation process:

- Establishment of the diagnosis of medical problems.

- Research of the right treatment.

- Verification of effectiveness of the treatment.

- Adjustment of the treatment if required.

The fifth stage is the continuous updating of the knowledge base to ensure its permanent consistency and sustainability. The more cases in knowledge base we have the more efficient is the case-based reasoning method. We are illustrating the approach that we are proposing with the study of an oncology case.

The remainder of this paper is organized in four sections. Section 2 provides the theoretical background and motivating issues about telemedicine and case-based reasoning. In the first part of Section 3, we describe the proposed architecture with its detailed steps for purposes of development in the suggested methodology. In the second part of Section 3 , it is provided a real case study from the oncology domain. Section 4 presents a discussion of the achieved and expected results. Section 5 gives the conclusion with outline descriptions of provided contribution in the research work presented in this paper.

\section{Telemedicine and case-based reasoning}

In this section after showing the interest of using case-based reasoning (CBR) in telemedicine we will mention a few recent works addressing CBR and telemedicine. And at the end we will also show the innovative aspects of the proposed research approach.

\subsection{The case-based reasoning paradigm}

The case-based reasoning copies the human behavior. It resolves problems seeking similar cases and adapting them. $\mathrm{CBR}$ is a reasoning paradigm that instead of relying on general rules or models chooses the specific knowledge contained into already solved instances of problems [2]. It is formalized as four-step process:

- Retrieve: find similar cases.

- Reuse: adapt and use similar case to resolve a new problem.

- Revise: adjust the new solution.

- Retain: store the resulting experience.

The quality of case-based reasoning method depends primarily on a good representation of cases in the retrieve step (it means to understand current case in relation to old cases in knowledge base) and the richness of knowledge base. In other words, the development of the case-based reasoning process is driven by the following activities [4]:

- Adapting old solutions to meet new demands.

- Using old cases to explain new situations.

- Using old cases to critique new solutions.

- Reasoning from precedents to interpret a new situation.

The rationale for using the case-based reasoning process is to support the formalization of reasoning procedures for collaborative medical acts in telemedicine.

In fact, this paradigm is similar to the physician's reasoning regarding the assessment of news cases in comparison with reported cases and eventually adaptation of retrieved solutions (if this is necessary).

Furthermore, CBR has methodological variations and systemic approaches allowing the use of appropriate technologies, with a consistency of system application guidance and flexibility of services. 


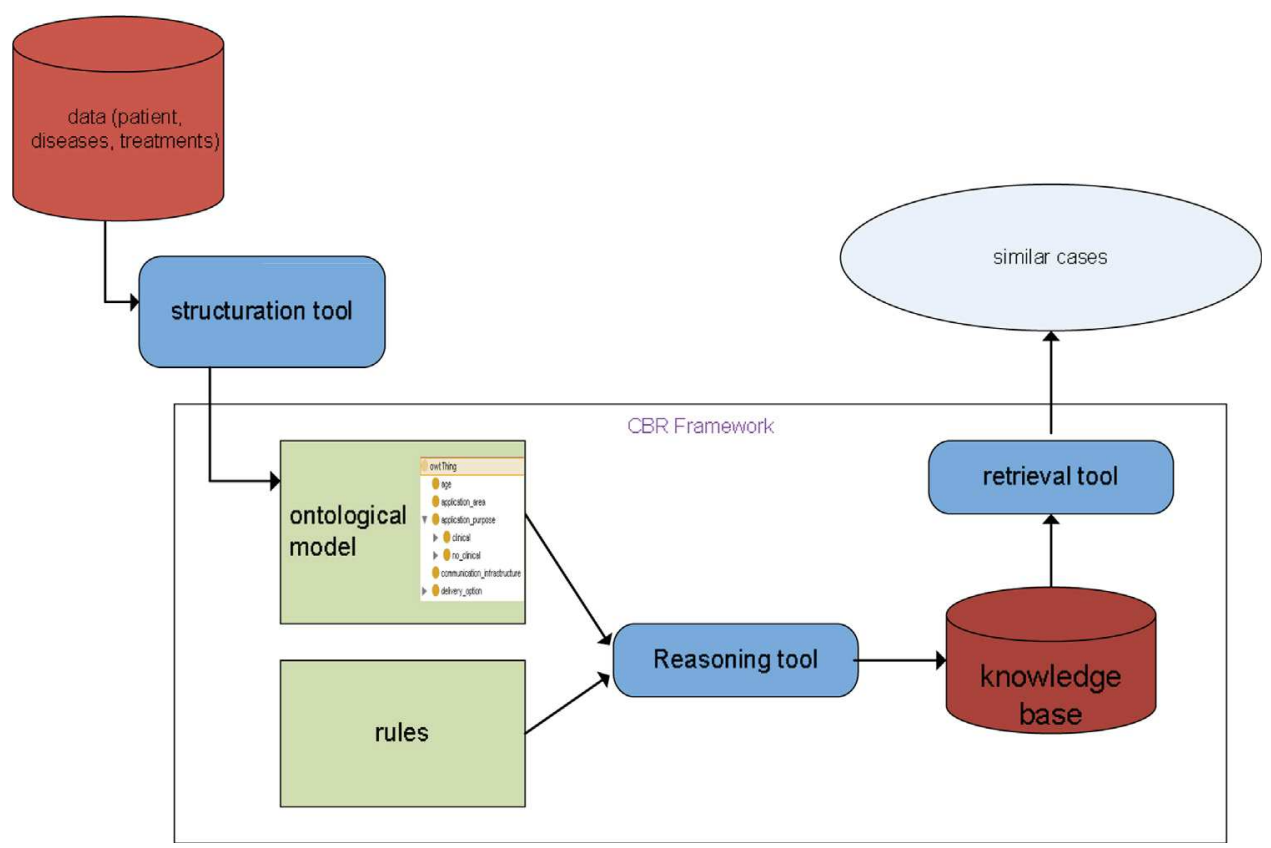

Fig. 1 - Proposed architecture.

In terms of implementation practices we can describe four main types of case-based reasoning [5]:

- Case-based reasoning using nearest neighbor: this is the most widely used technology in CBR. The similarity between target case and each case in the knowledge base is determined in order to rank them.

- Case-based reasoning using induction: this method partitions cases in clusters. Cases in each cluster are similar, and as it is assumed (usually correctly) that cases with similar descriptions of problems (where possible its key components) will refer to similar problems and hence similar solutions.

- Case-based reasoning using fuzzy logic: fuzzy logic deals with approximate reasoning with variables possibly having a truth value that ranges in degree between 0 and 1 . Furthermore, the attributes of cases can be represented by linguistic variables associated with specific functions.

- Case-based reasoning using database technology: database technology can be used to implement case-based reasoning. The problem is that the databases use only structured information and usually employ a number of exact matches to answer queries.

\subsection{State of the art}

Many works have already addressed telemedicine. These works differ in terms of telemedicine acts covered and methods used to practice telemedicine.

Authors in [6] suggest a different method (conceptual graphs and argumentative logic) and focus on tele-expertise act. They propose a framework for the decision making process to ensure traceability in teleexpertise. They visualize reasoning by CoGui [7] software that includes functions to edit constraints and rules for the assistance in the reasoning process. In telemonitoring act, the purpose of Meenu Singh et al.'s works in [8] is to use a tool (handheld teleelectrocardiogram) to identify heart condition in a rural underserved population. The objective of this study was clinical validation of this electrocardiogram as a screening tool for evaluation of cardiac diseases in the rural population. Some activities of teleconsultation are already done in the region of Midi-Pyrénées in France as part of a health project led by GCS (health care cooperation consortium) [9] Télésanté Midi-Pyrénées. A health information system is available for physicians in order to deliver remote healthcare services. In teleassistance, Giorgio [10] proposes a medical device for health monitoring and teleassistance applications. This system allows real-time rescue of patients having heart failure and high risk of life.

Some works are related directly to the application of CBR in medical domain. Montani et al. [2] propose a case-based decision tool. Their aim is to help doctors in diabetes therapy revision through an intelligent retrieval of data related to past cases similar to the target one. In our approach we propose case-based reasoning architecture.

The non-exhaustive reading of works related to the medical applications of case-based reasoning $[2,4,8]$ shows that they mainly use the basic CBR process with four steps. In our reasoning approach, due to the sensitivity about the complex issues of the medical field, we add another step in the CBR process in order to increase the reliability of the medical reasoning processes.

In what follows, we will present in detail our architecture enriching the CBR process and then an illustrative application of the proposed approach in oncology.

\section{Research methods}

In this section we will first list and explain the constitutive elements of our architecture. Then we will study the relation 


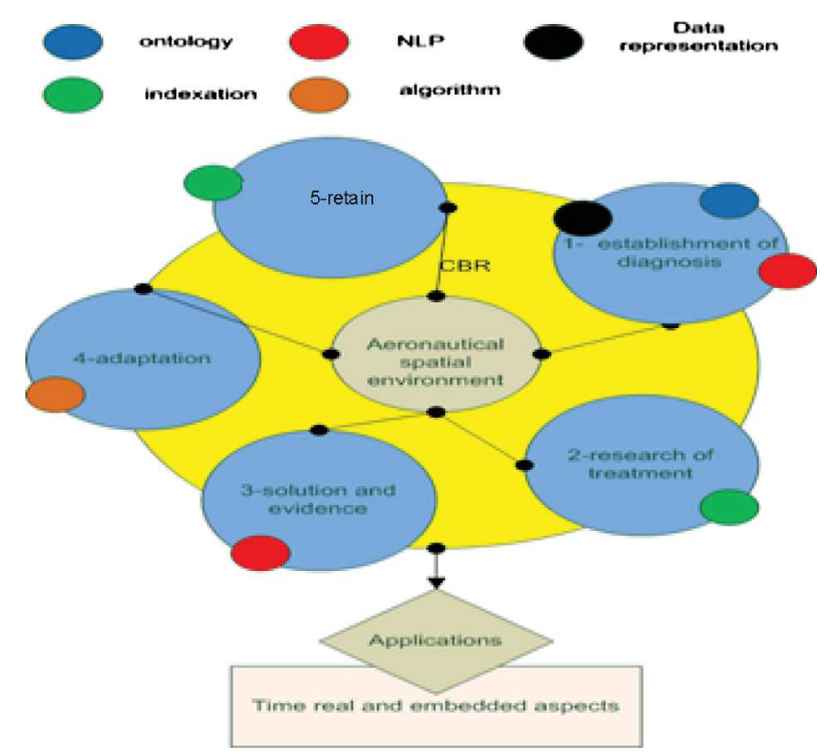

Fig. 2 - CBR process.

between the elements and how to combine them to build an efficient reasoning system able to provide effective support in telemedicine.

\subsection{Proposed architecture}

Fig. 1 shows the proposed architecture that is intended to be easily expandable. The stage of structuring and conceptualization is not presently fully automated but it is made in collaboration with experts of the medical field (particularly in oncology and geriatrics). The complete automation of this architecture will be the object of future studies [11].

The proposed architecture (Fig. 1) combines ontologies and rules in reasoning tool that formalizes knowledge modeling for the description of collaborative practices and information retrieval.

An ontological model is obtained from patients, diseases, and treatment data by the structuring tool. Then a reasoning tool (taking into account the specified constraints and rules) can check the consistence of ontology and make inferences. The result will be a knowledge base which will be in communication with the retrieval tool aiming to find similar cases.

We have in Fig. 2 the CBR framework (with five steps) based on the proposed architecture. Each step would be performed using suitable tools for natural language processing, data representation, ontology modeling, indexation and information retrieval.

During research of treatment (first stage of reasoning), we will apply successively two techniques often used separately: case-based reasoning using induction then case-based reasoning using nearest neighbor. The purpose is to make case retrieval faster but also efficient. In fact a partition of the cases base in different clusters allows to reduce the research space and to make similarity calculations on a small group on which the reasoning procedures will have to focus for the determination of the more suitable cases.

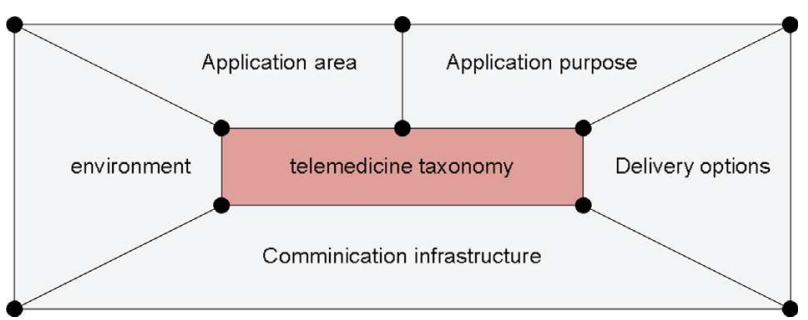

Fig. 3 - Medical taxonomy.

\section{- Ontology}

In the context of computer science, ontology is used for information organization and knowledge representation. Defined originally in 1993 by Thomas Gruber [12] as an explicit specification of a conceptualization, ontology is designed for knowledge sharing. Ontology contains a hierarchical description of concepts and relationships that can formally exist for an entity or a community of entities. The development of ontologies is essential to formalize a common vocabulary for distributed collaboration in a particular domain. Four categories of ontology can be distinguished depending on subject of the conceptualization [13].

- Application ontologies: statements of the meaning of terms to model knowledge needed for a specific application.

- Domain ontologies: conceptualization of a particular domain (e.g. medicine, automobile industry, oenology).

- Generic ontologies: upper conceptualization applicable across a varied range of domain sets.

- Representation ontologies: explanation of the conceptualizations that underpin knowledge representation formalisms.

- Natural language processing (NLP)

NLP operates as a practical tool within the human-computer interaction framework and encompasses language understanding or language generation to cover tasks such as information retrieval, information extraction and speech processing. Natural processing language may increase the feasibility and effectiveness of more applications in the medical domain by making it easier to structure information from different sources [11]. In fact it can increase the effectiveness of communication means (e.g. proper use of the medical devices) to make them more user-friendly for collaborative teams. NLP will also facilitate the conversion of medical information from computer databases into understandable human language.

Before the description of the 5 stages, we will focus on a most important notion in case-based reasoning: the "case". It is generally defined as a set of features representing a problem, its solution, and indications about how the solution is generated. Case will be considered like a vector of concepts characterizing a situation with an ontology modeling.

In Table 1, for each step of our architecture, we describe the associated tasks and tools used for the implementation of the CBR process. 


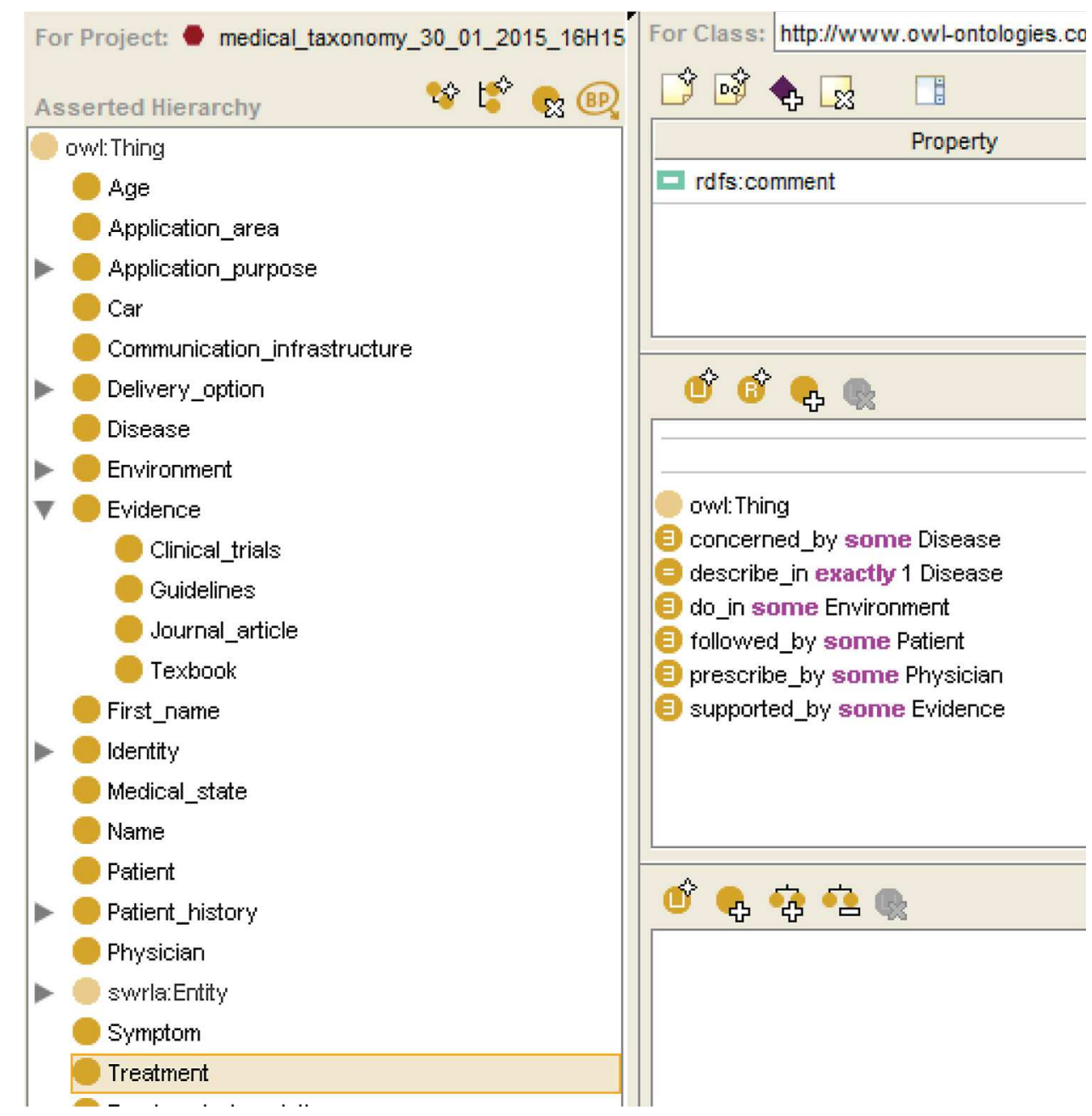

Fig. 4 - Medical ontology.

\subsubsection{Taxonomy}

Taxonomy is a classification of concepts, with the principles underlying such an arrangement. Taxonomy is often seen as the minimal structure of ontology in computer science.

Table 1 - Tasks and tools used for the CBR process.

Steps Tasks Tools

\begin{tabular}{cll}
\hline $\begin{array}{r}\text { Establishment } \\
\text { of diagnosis }\end{array}$ & Case definition & $\begin{array}{l}\text { Taxonomy: } \\
\text { definition of system } \\
\text { dimensions } \\
\text { Ontology: knowledge } \\
\text { representation } \\
\text { NLP: data } \\
\text { acquisition }\end{array}$ \\
& & $\begin{array}{l}\text { Data representation: } \\
\text { data modeling } \\
\text { Indexation }\end{array}$ \\
Induction similarity \\
Solution and \\
evidence & $\begin{array}{l}\text { Mapping current to } \\
\text { the target cases }\end{array}$ & $\begin{array}{l}\text { Check effectiveness } \\
\text { of solution } \\
\text { Adaptation }\end{array}$ \\
Adapt solution to & Ontology \\
patient & Update knowledge & Data storage \\
Retain & base & \\
\hline
\end{tabular}

As described earlier the domain ontology contains a hierarchical description of concepts, which corresponds to a taxonomic structuration of classes with respect to their specialization relation.

In [14] Tulu et al. proposed a taxonomy structuring telemedicine domain. They identified five dimensions (Fig. 3): (1) application purpose, (2) application area, (3) environmental setting, (4) communication infrastructure, and (5) delivery option. Application purpose and application area represent the medical part and the last three dimensions are tools and places to do telemedicine.

Table 2 provides some examples of medical taxonomy content that is applicable in each dimension.

Taking into account the taxonomy presented above, we built domain ontology of medical field with the open-source ontology editor called Protégé ${ }^{\circledR}$ [15]. Fig. 4 shows a segment of our ontology with treatment's assertions.

The most important concepts are patient and treatment. The case representation describes the treatment and the patient is the main component of this description.

Patient concept

This concept summarizes all considered attributes in the characterization of a patient condition. It is the information required for the recognition of symptoms, the establishment 


\section{Table 2 - taxonomy dimensions.}

\begin{tabular}{|c|c|}
\hline Dimension & Contain \\
\hline Application area & $\begin{array}{l}\text { Cardiology } \\
\text { Dermatology } \\
\text { Neurology } \\
\text { Oncology } \\
\text { Infectious diseases }\end{array}$ \\
\hline Application purpose & $\begin{array}{l}\text { Non clinical: } \\
\text { Research } \\
\text { Patient education } \\
\text { Evaluation research } \\
\text { Clinical: } \\
\text { Teleconsultation } \\
\text { Telemonitoring } \\
\text { Teleexpertise } \\
\text { Teleassistance } \\
\text { Drugs trials } \\
\text { Rehabilitation } \\
\text { Patient case review }\end{array}$ \\
\hline Delivery option & $\begin{array}{l}\text { Devices: } \\
\text { Electrocardiogram } \\
\text { A-ray scanner } \\
\text { Camera } \\
\text { Application: } \\
\text { Natural language processing } \\
\text { Interactive video } \\
\text { Interactive audio } \\
\text { Real time communication }\end{array}$ \\
\hline Environment sittings & $\begin{array}{l}\text { Hospital } \\
\text { Patient's home } \\
\text { Medical center }\end{array}$ \\
\hline $\begin{array}{l}\text { Communication } \\
\text { infrastructure }\end{array}$ & $\begin{array}{l}\text { Optical fiber } \\
\text { ADSL } \\
\text { GSM } \\
\text { Satellite } \\
\text { ATM }\end{array}$ \\
\hline
\end{tabular}

of the diagnosis with the means available to the health professionals.

Fig. 5 shows how are organized the additional concepts required to characterize the component "patient".

Treatment concept

In the tree structure of treatment concept, we find all features of medical system (Fig. 6):

- The patient: a person who is a recipient of health care and associated treatments.

- The disease: an abnormal condition that affects a patient with certain symptoms and signs.

- The physician: a medical professional who provides the diagnosis and treatment of diseases.

- Environment: hospital, patient home, etc.

- Means and options: devices and applications;

- Prescriptions: a medical instructions of care (e.g. by drugs) or complementary investigations transcribed by a physician.

- Evidences: scientific proofs that serve to support clinical decision-making.

- Palliative care: therapies that relieve symptoms of diseases without curative intent.

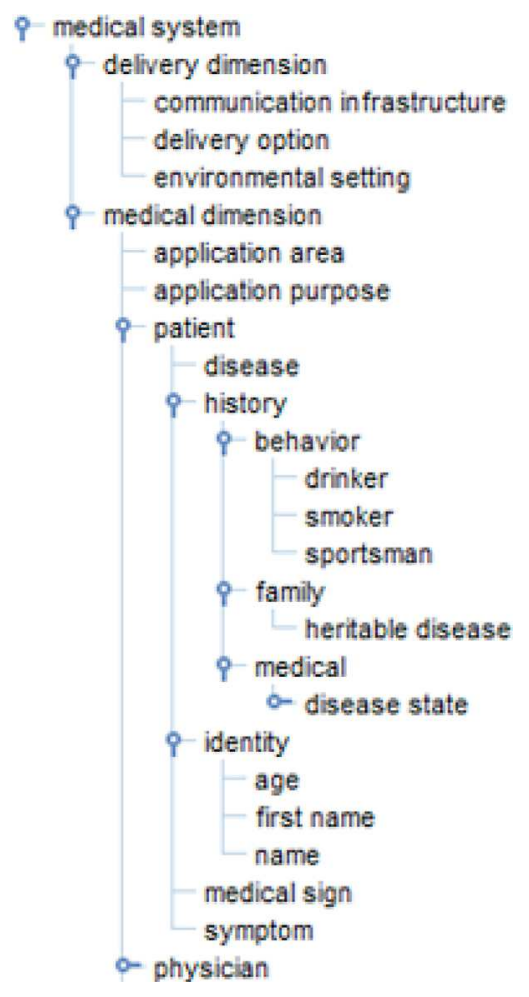

Fig. 5 - Patient concept definition.

- Alternative medicine: naturopathic and traditional medicine practices (e.g. homeopathy, African and Chinese medicine).

- Chemotherapy: treatment of cancer with chemical substances (chemotherapeutic agents).

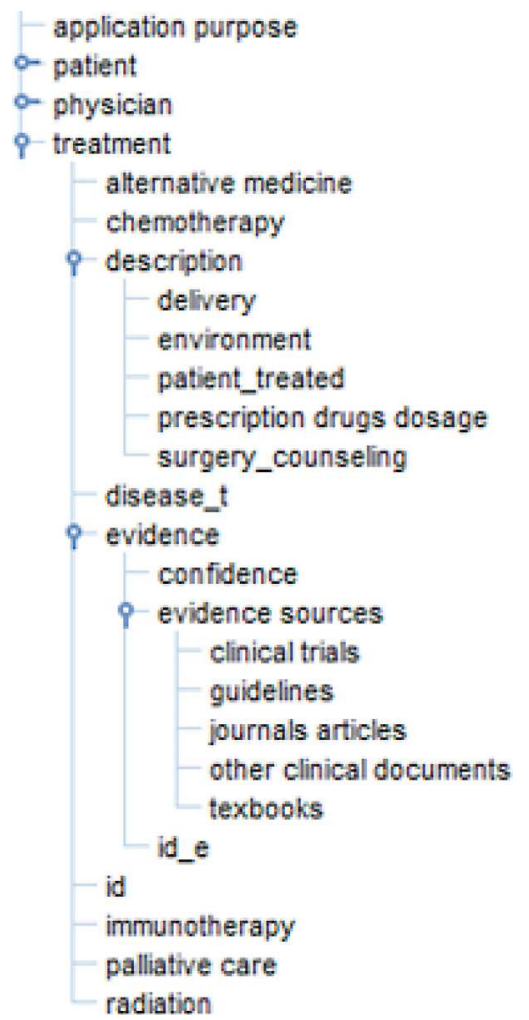

Fig. 6 - Treatment's concept definition. 


\begin{tabular}{|c|c|c|c|}
\hline Concepts & $\begin{array}{l}\text { Abbreviation } \\
\text { for table }\end{array}$ & Type & Values \\
\hline \multicolumn{4}{|l|}{ Patient treated } \\
\hline Name & pin & String & \\
\hline First name & pifn & String & \\
\hline Age & pia & Integer & \\
\hline Symptoms & ps & $\begin{array}{l}\text { Vector of } \\
\text { string }\end{array}$ & \\
\hline Behavior & $\begin{array}{l}\text { phbs, phbd, } \\
\text { phbsp }\end{array}$ & String & $\begin{array}{l}\text { [Smoker, } \\
\text { drinker, } \\
\text { sportsman] }\end{array}$ \\
\hline Heritable disease & phfhd & String & \\
\hline Medical state & phm & $\begin{array}{l}\text { Vector of } \\
\text { string }\end{array}$ & \\
\hline \multicolumn{4}{|l|}{ Physician } \\
\hline Name & & String & \\
\hline Specialty & & String & \\
\hline Type & & Integer & \\
\hline \multicolumn{4}{|l|}{ Disease } \\
\hline Disease & $\mathrm{pd}$ & $\begin{array}{l}\text { Vector of } \\
\text { string }\end{array}$ & \\
\hline $\begin{array}{r}\text { Alternative } \\
\text { medicine }\end{array}$ & & String & [Yes, no] \\
\hline Palliative care & & String & [Yes, no] \\
\hline Chemotherapy & & String & [Yes, no] \\
\hline \multicolumn{4}{|l|}{ Evidences } \\
\hline Confidence & & Float & \\
\hline Evidence source & & $\begin{array}{l}\text { Vector of } \\
\text { string }\end{array}$ & $\begin{array}{l}\text { [Clinical } \\
\text { trials, } \\
\text { guidelines, } \\
\text { journal } \\
\text { articles, } \\
\text { textbook, } \\
\text { etc.] }\end{array}$ \\
\hline
\end{tabular}

3.1.2. Case definition

Table 3 shows features defining a case. For each attribute we have the possible values and their type.

\subsubsection{Case-based reasoning process}

In Table 4 we summarize each step with the main attributes.

3.1.3.1. Establishment of diagnosis. At this level, the aim is to identify the patient's disease or health problem and clinical condition. The establishment of a diagnosis corresponds to the first stage of our case-based reasoning. The study of medical signs and symptoms (for example comparison with symptoms in International Classification of Diseases (ICD) gives a set of diseases). An investigation of key patient parameters (namely: age, medical history (lifestyle and family)), clinical trials and books provides us with the initial means for achieving a relevant diagnosis and treatment of the considered disease. The taxonomic component of domain ontology and the data representation are the modeling elements used for the formal representation of medical cases (Fig. 3). The concepts used for this stage are presented in Fig. 7.

In the process for establishing the diagnosis of a disease, we will first compare symptoms between the current case and previous medical cases recorded in the knowledge base. This comparison will be done with a diagnosis algorithm (Fig. 8) or a local similarity function of tools like Protégé ${ }^{\circledR}$. If this is

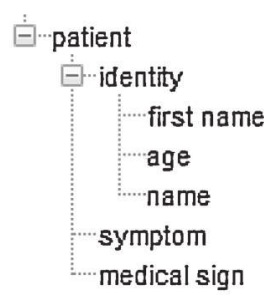

Fig. 7 - Patient concept.

enough to confirm a disease we can start the search for a treatment or else we use other sources like International Statistical Classification of Diseases and Related Health Problems, usually called by the short-form name International Classification of Diseases (ICD).

3.1.3.2. Research of treatment. After the establishment of a diagnosis, a set of possible treatments can be identified and their prioritizations based on the patient's needs. The choice of treatment depends on the comparison of current patient factors (e.g. age and medical condition) with the entire candidate treatments corresponding to the diagnosis established. In order to do this, we will calculate similarities with the following equation:

$s=\sum_{i=1}^{n} f(T i, S i) \times \alpha i$

s: similarity between the current case of the patient involved and the recorded medical cases of past patients; $\mathrm{T}$ : attribute of target case; $S$ : attribute of source case; i: current attribute; $n$ : number of attribute; $\alpha$ : the weighting of attributes in order to rank them according to their importance and priority scales of the medical context. For example, the lifestyle of a patient can be considered most importance that his age, for falls prevention in the elderly.

This stage provides a pre-treatment assessment, a set of treatments that we will weight in stage 3 (solution and evidence).

3.1.3.3. Solution and evidence. This is a critical step of the execution of the proposed method, in particular regarding its effectiveness. The most credible and reliable type of treatment is that which provides an analysis of the sources of evidence and experts' opinions [16].

Sources of evidence:

Each treatment (case) is registered as follows (Fig. 9).

Effective treatments and their associated references can be identified using ontology alignment techniques in digital technologies for healthcare [17]. If proposed references allow choosing one treatment then we proceed to the next stage or else we will take account of the experts' opinions. References can be:

- A review article: presenting research results. Article must be reviewed by experts within the same subject area before publication. 
Table 4 - Concepts and steps mapping.

\begin{tabular}{|c|c|c|}
\hline Step & Attribute & Use \\
\hline Establishment of diagnosis & Patient & $\begin{array}{l}\text { The study of medical signs, symptoms and } \\
\text { patient's history provides diagnosis }\end{array}$ \\
\hline Research of treatment & Disease & $\begin{array}{l}\text { Case-based reasoning using induction to } \\
\text { partition diseases case-based reasoning using } \\
\text { nearest neighbors to find most similar cases }\end{array}$ \\
\hline Solution and evidence & $\begin{array}{l}\text { Patient } \\
\text { Disease } \\
\text { Evidence }\end{array}$ & $\begin{array}{l}\text { Study of solution and evidence is done taking } \\
\text { into account diseases and patient features }\end{array}$ \\
\hline Adaptation & $\begin{array}{l}\text { Patient } \\
\text { Disease } \\
\text { Environment } \\
\text { Evidence } \\
\text { Delivery }\end{array}$ & $\begin{array}{l}\text { The treatment will be customized to patient and } \\
\text { environment }\end{array}$ \\
\hline Retain & Treatment & $\begin{array}{l}\text { Storage of the resulting experience (case with } \\
\text { diagnosis and treatment) in the knowledge base }\end{array}$ \\
\hline
\end{tabular}

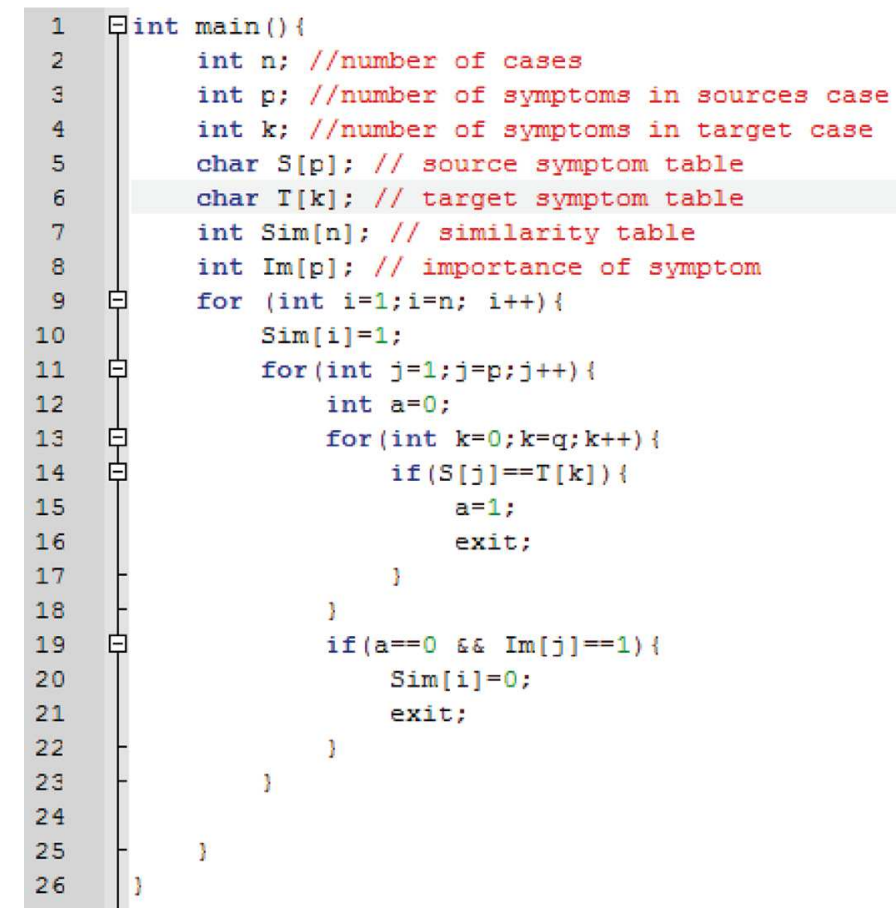

Fig. 8 - Diagnosis algorithm.

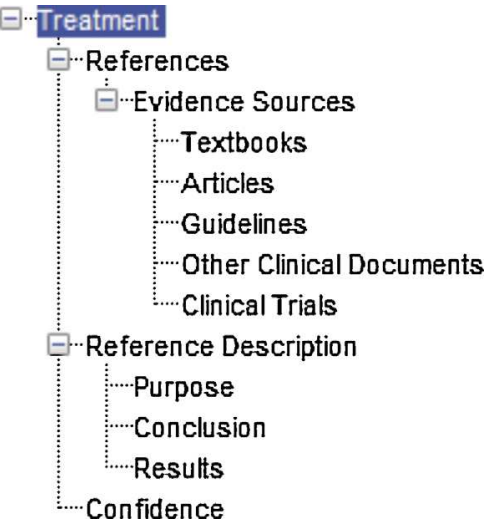

Fig. 9 - reference concept.
- Guidelines: showing a course of action. Guidelines may be issued and used by governmental or private organization and following them is not mandatory.

- A clinical trial is a scientific research study on human subjects intending to assess effectiveness and tolerance of a prospective diagnostic or therapeutic intervention.

3.1.3.4. Adaptation. Generally, it is difficult to obtain a fully similar case to previous ones. We are required to make reasonable adaptations to match the current medical environment and the medical needs of the patient concerned. There is a wide variety of medical options to meet the different anatomical and physiological characteristics of patients suffering from the same disease. The treatment approach typically depends on the category and critical nature of the patient's parameters. For example, on a medical prescription the indications 


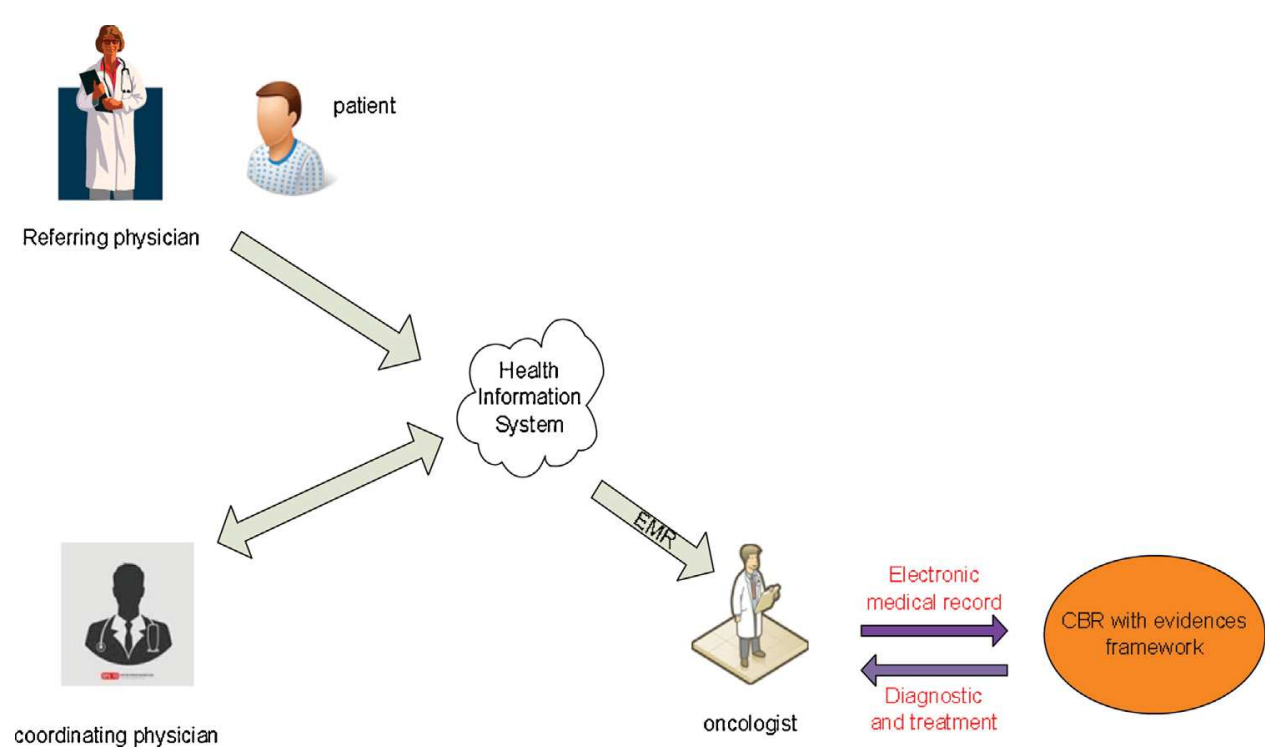

Fig. 10 - Collaborative model of telemedicine delivery.

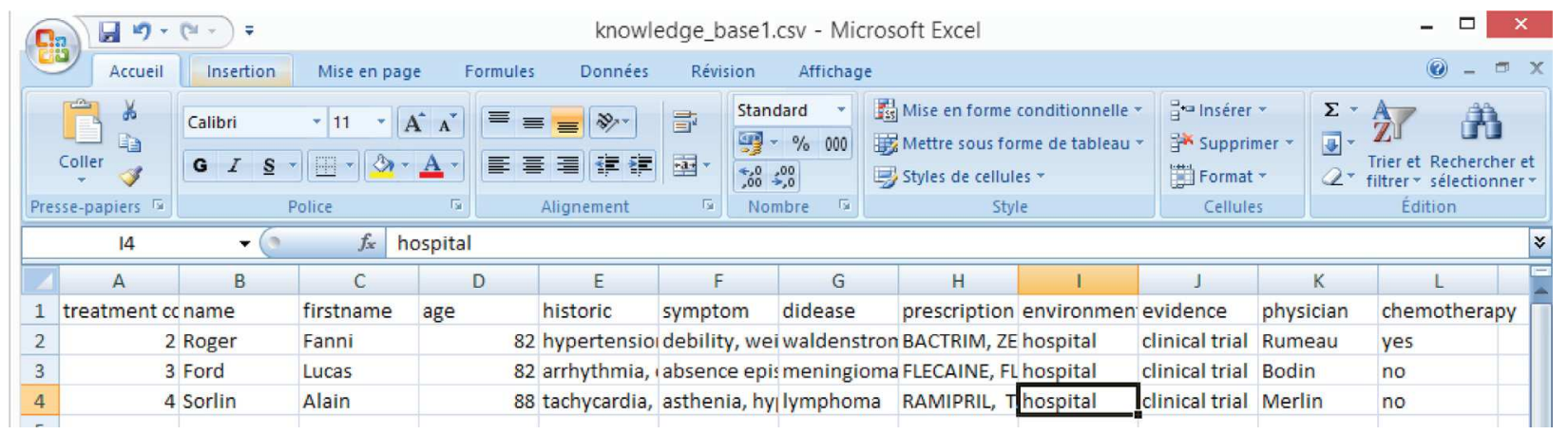

Fig. 11 - Cases import in the knowledge base.

and dosage recommendations depend on variables such as the severity and chronicity of the disease or the age and gender of patient. The choice of the best treatment is determined by a considerable similarity among cases in their attributes and the adaptation of the treatment should be based on the patient's condition, the clinical response and the possible or occurring side effects.

3.1.3.5. Retain. It marks a significant stage in the information management cycle of case-based reasoning. This is contributing to support the reuse of the recorded cases with their associated reasoning (establishment of diagnosis or search for treatment) for information retrieval, knowledge and information sharing and decision making. The structuration of cases base is determined by the indexing functions and the models of memory organization (simple model, model with dynamic memory or model based on categories) of the case-based reasoning system. This structuration, for example, can use a network of categories and cases to explain organizational patterns according to the characteristics described by a name, a value and a level of importance regarding the membership of a case in a category (Table 5).
The effective step of retaining depends on the obtainability of the essential bibliography, procedures, methods and services to achieve the efficient data structuration and the availability of significant information.

\subsection{Case study: oncology case}

Telemedicine is predominantly used for managing chronic diseases or critical medical domains, such as cardiology, radiology, ophthalmology or oncology [18].

In our case study, and in the context of supporting the development of remote collaboration between health professionals, we use the model of teleexpertise defined by the GCS Télésanté Midi-Pyrénées (Fig. 10). The referring physician needs a certain expertise regarding complex medical

\begin{tabular}{lccc} 
Table $\mathbf{5}$ - Case organization. & & \\
Type a & Type b & Type c & Type n \\
\hline Treatment a1 & Treatment b1 & Treatment c1 & Treatment n1 \\
Treatment a2 & Treatment b2 & Treatment c2 & Treatment n2 \\
Treatment a3 & Treatment b3 & Treatment c3 & Treatment nq \\
\hline
\end{tabular}




\section{D}

\section{historic}

hypertension, cataracte

arrhythmia, dislipidemia

debility, weight loss, arthrosis

tachycardia, varicosity, appendectomy, hemorrhoidectom asthenia, hyperthermia, nighttime sweats, colon polyps appendectomy, sigmoid surgery, breast cancer artthrosis, asthenia, hyperthermia

Fig. 12 - Symptoms and histories of patients.

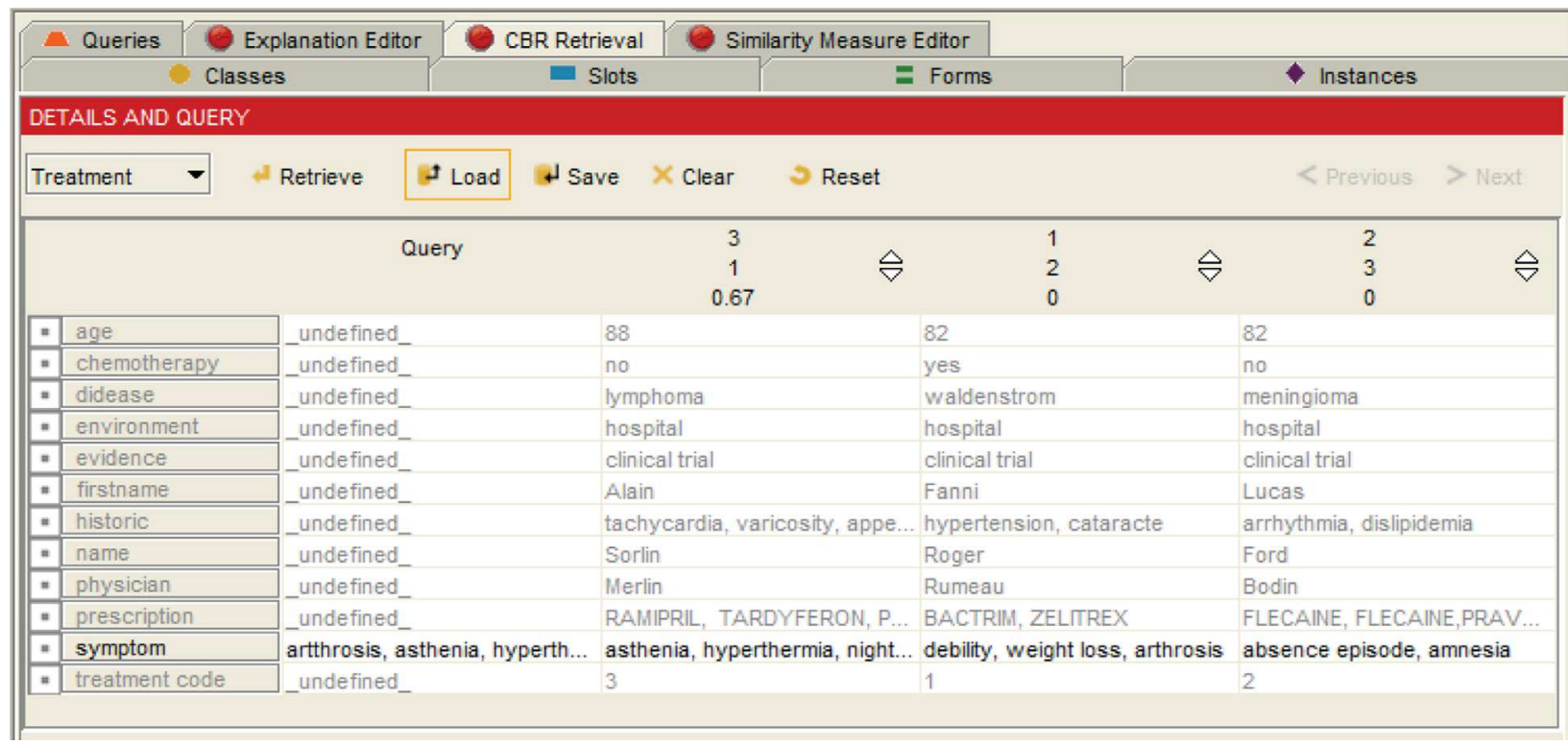

Fig. 13 - Establishment of diagnosis.

problems and he made the request (in a synchronous or asynchronous manner) on the health information system (SIS) of the GCS. The coordinating physician contacts the required physician to obtain an expert medical advice and organizes the collaborative medical session according to the contextual characteristics of the target case. In the medical situation described in this case study; the required physician is an oncologist who interacts with the case-based reasoning system. However, the oncologist needs to take into account the opinions of the requiring physician; the patients and their families. The primary sources of data for use in this study are real anonymized medical records. A list of prospect records of data from observational databases was asked from an expert physician working in a geriatric oncology unit of a university hospital in Toulouse. It was required that the records would include the establishment of the diagnosis and the treatment

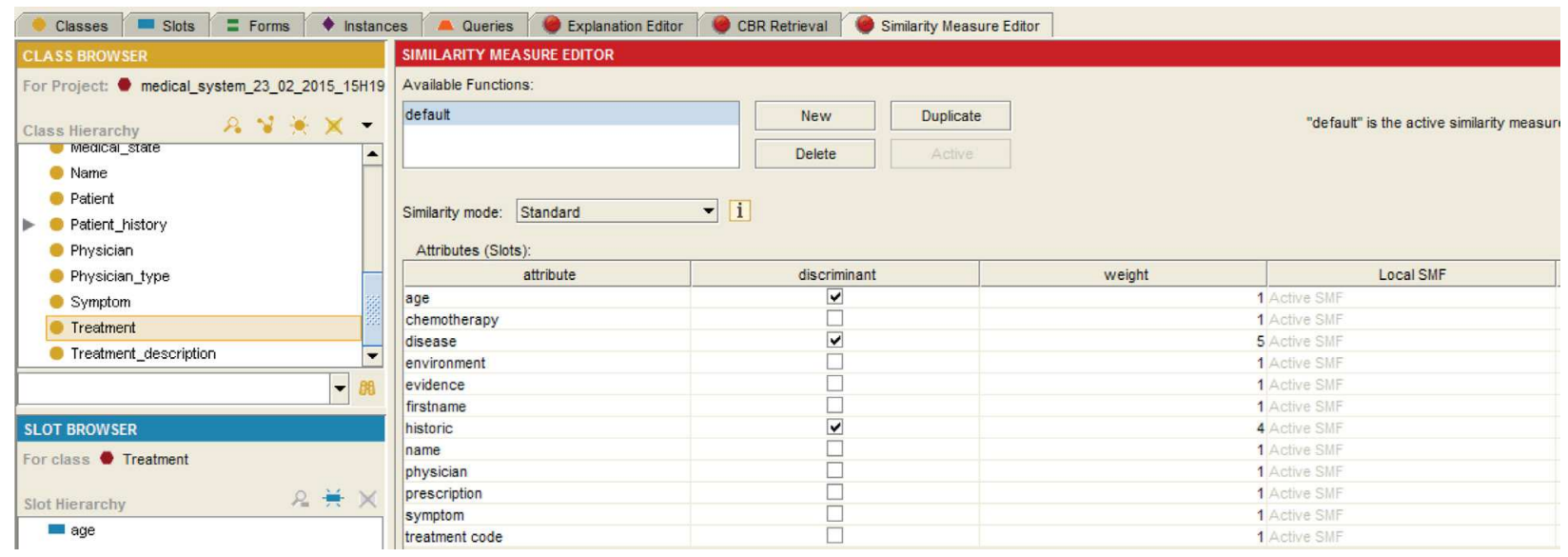

Fig. 14 - Global similarity measure. 


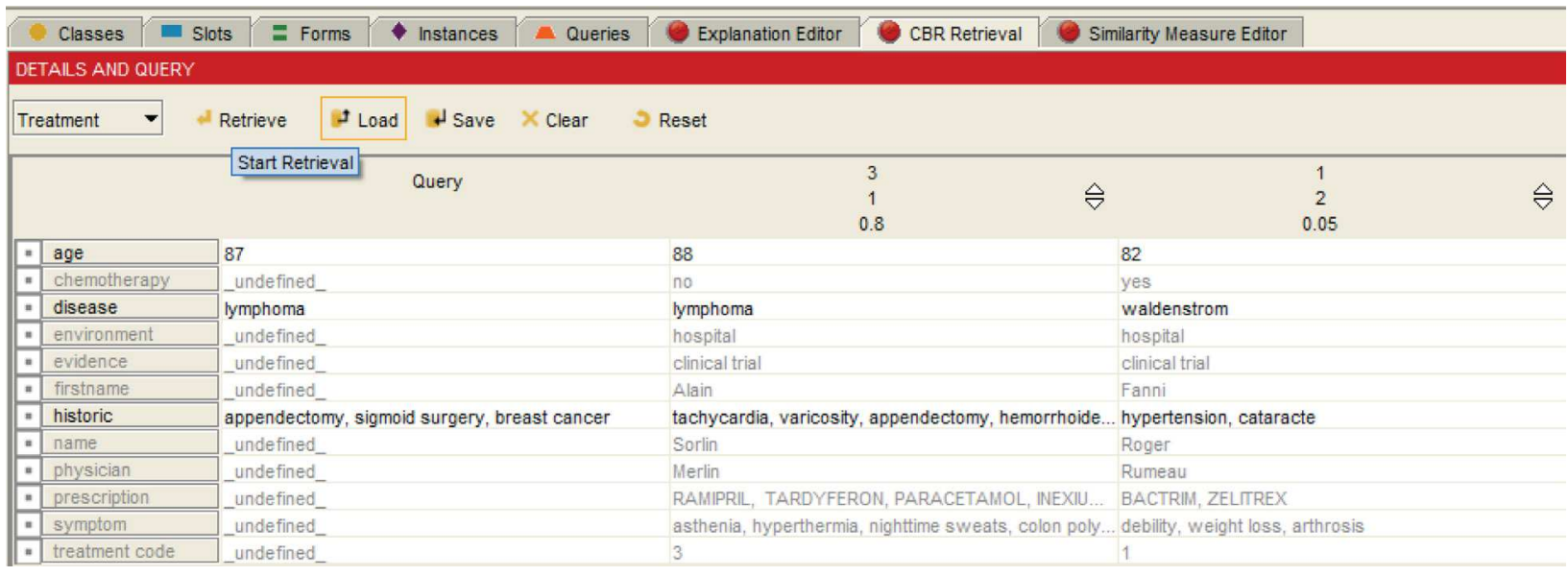

Fig. 15 - Research of treatment with details and query.

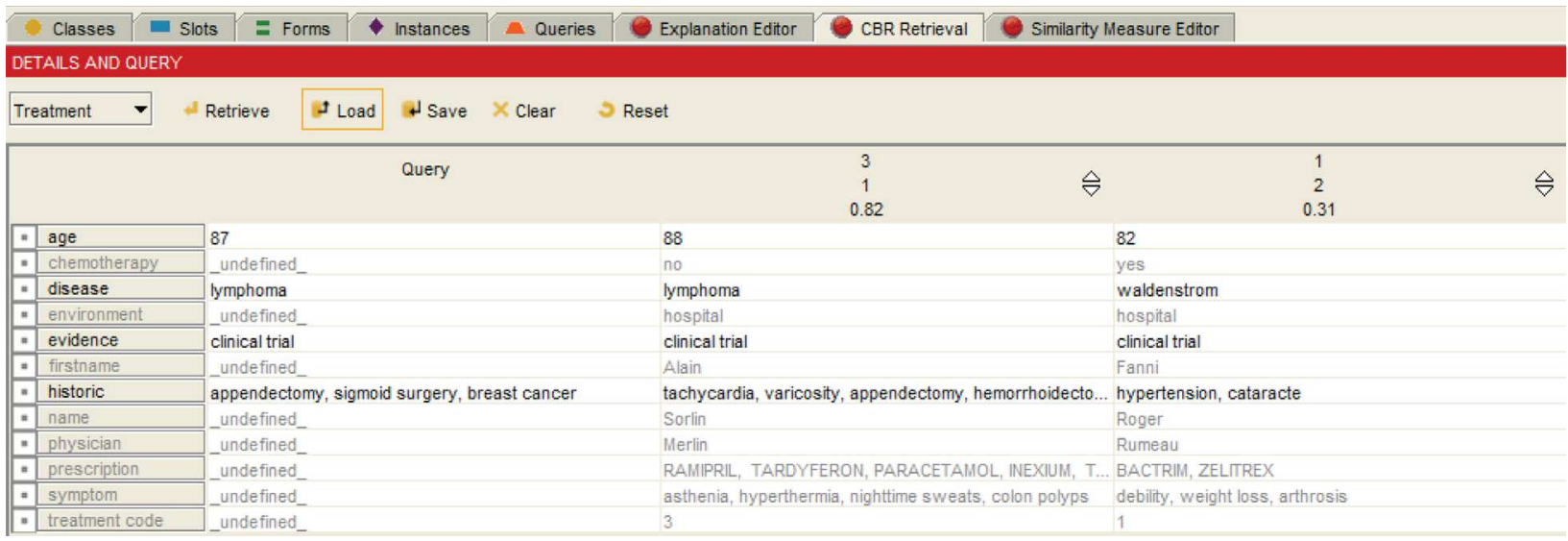

Fig. 16 - Case with verifiable evidences.

of the condition. The physician provided a list of 10 names, a physician involved in the study checked the records for comprehensiveness, and then from the 8 remaining anonymized records four were randomly selected. Three cases were integrated in the target knowledge base and the forth one was used as the test case provided for the execution of case-based reasoning with evidences.
Even if our study is in oncology, this framework can be applied on any branch of medicine. In Fig. 11 we have 3 cases (treatments) in comma-separated value (CSV) files used to import the attributes of the cases. CVS is a shared file format that is commonly supported by scientific applications to represent sets or sequences of records.

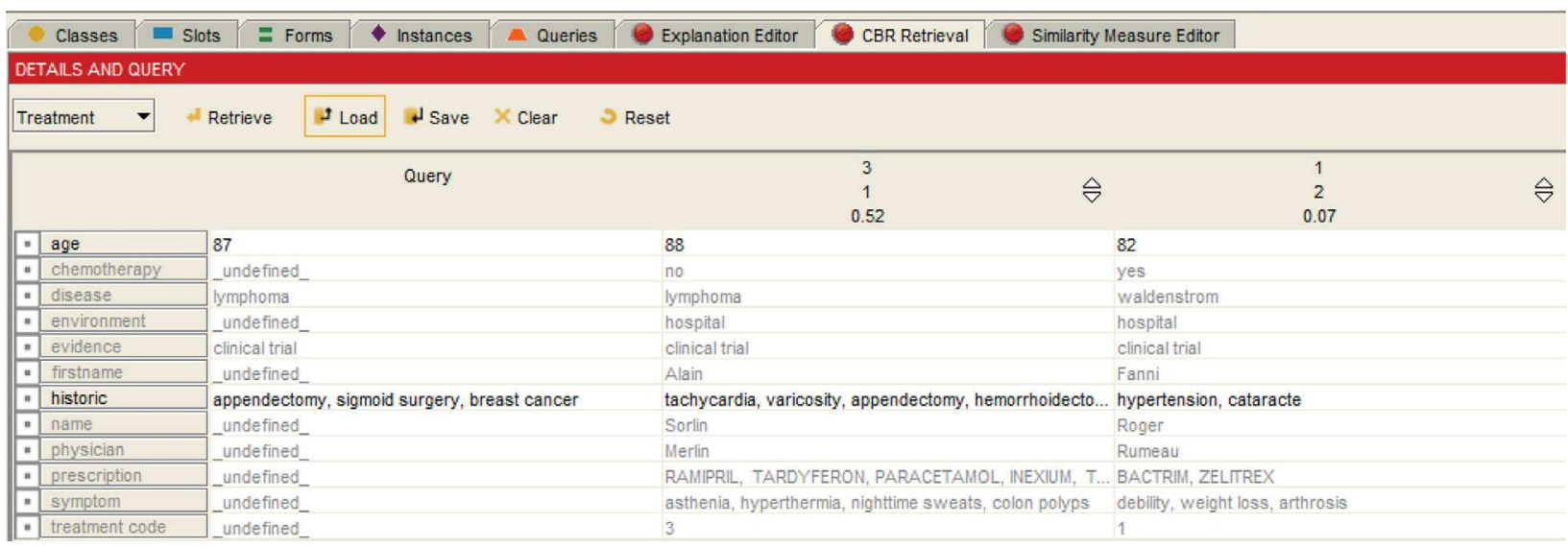

Fig. 17 - Adaptation of the solution. 
In fact for the case study, we use Protégé $3.5^{\circledR}$ to check the consistence of the ontology and MyCBR ${ }^{\circledR}$ plug-in to compute the case based reasoning process.

\subsubsection{Oncology case: establishment of diagnosis}

According to the first stage in the case-based reasoning process, the establishment of diagnosis is performed by comparing symptoms characteristic of the patient's disease. This is achieved mainly through an analysis of similarities symptoms of patients in the data structures. The patient history can be used to enable prompt and reliable diagnosis (Fig. 12).

Activating only the attribute symptom, we get a percentage of symptoms found in the patient in comparison to the cases in the knowledge base. The disease of the matching case is lymphoma (as diagnosed by the experts) (Fig. 13).

\subsubsection{Oncology case: research of treatment}

The following figure shows our approach to search a treatment. Each field describing the concept treatment has a weight depending on its importance (Fig. 14).

We can start retrieval after editing patient information. This gives the result presented in Fig. 15. Particularly, the treatment 1 corresponds with $80 \%$ in the considered case.

\subsubsection{Oncology case: solution and evidence}

We have an objective clinical trial certifying the effectiveness of treatment 1 and the experts' opinions can confirm this point (Fig. 16). In short, the application of the adopted approach is illustrated by the two following steps:

(1) Step 1: simple matching: Treatment $1=80 \%$ and Treatment $2=5 \%$.

(2) Step 2: matching with evidences: Treatment $1=82 \%$ and Treatment $2=31 \%$.

\subsubsection{Oncology case: adaptation}

Each stage or feature of medication depends on one or more attributes. For example dose of medicines depends on the age of patient, potential drug interactions or allergies (Fig. 17).

\subsubsection{Oncology case: retain}

The current case is registered according to the type of disease (Figs. 18 and 19).

\section{Discussion}

In the paper we presented a case-based reasoning framework applied to medical domain.

As it is described above our approach based on ontologies focuses on the main activities of medical professionals in telemedicine. Domain ontologies have already been proposed on diseases, drugs but there are few research works in telemedicine and EHealth attempting to define the treatment and bind it to the patient with his symptoms.

Our work is trying to embrace as a whole the medical decision system in its ecosystem (patients, treatment and diagnosis tools availability, available knowledge). The modular aspect of the proposed framework allows an easy incremental application or the incorporation of new modules such as other

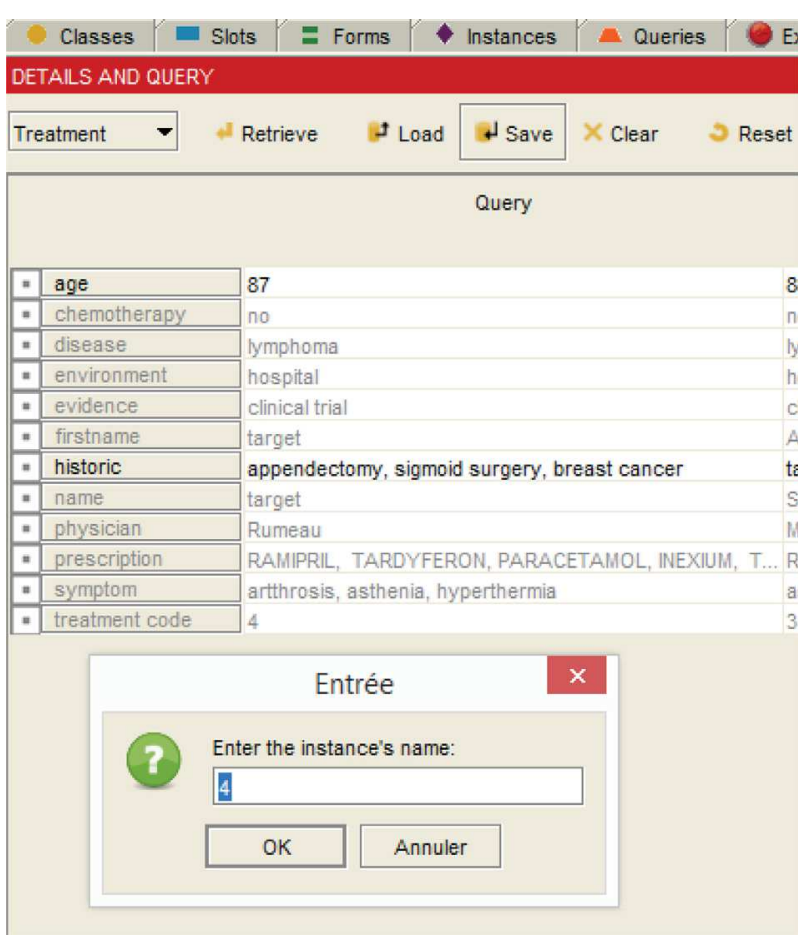

Fig. 18 - Case edition.

types of reasoning system (e.g. constraint solvers or deductive classifier) and information processing (e.g. natural language processing).

In our paper, both the source and the target cases are originating from the same team, with common uses in the naming of the symptoms, diseases and treatments. Moreover oncology is a medical specialty where care is highly normalized trough diagnosis and treatment protocols (e.g. Tumor-Nodes-Metastasis (TNM) Cancer Staging system [19]). When we will try the medical potential of our approach we will need source and target medical records from different teams. The next step will be to consider a medical specialty with more heterogeneous processes.

The establishment of the diagnosis and treatment is only based on the presence of the symptoms and their history. The chronology or the dynamics of the symptoms should also be taken into account, not only in the past but as the disease progresses and the management of patient care should adapt. Furthermore it must be a real structuration of symptoms that do not always have the same importance. This will allow taking into account for example pathognomonic character of some symptoms and the interest of the absence of some discriminating signs for the diagnosis.

Presently, medical research is mostly based on "evidence based medicine" [20] that emphasizes the integration of evidence from well considered and conducted research. Evidence-based practice uses guidelines and policies that incorporate evidence from scientific research in medical strategies and decisions. It can be applied in population-level decisions resulting from meta-analysis comparing the average effect on two similar normal populations, one receiving the procedure, the other used as a control. The similarity of the populations is requiring a screening with inclusion and 


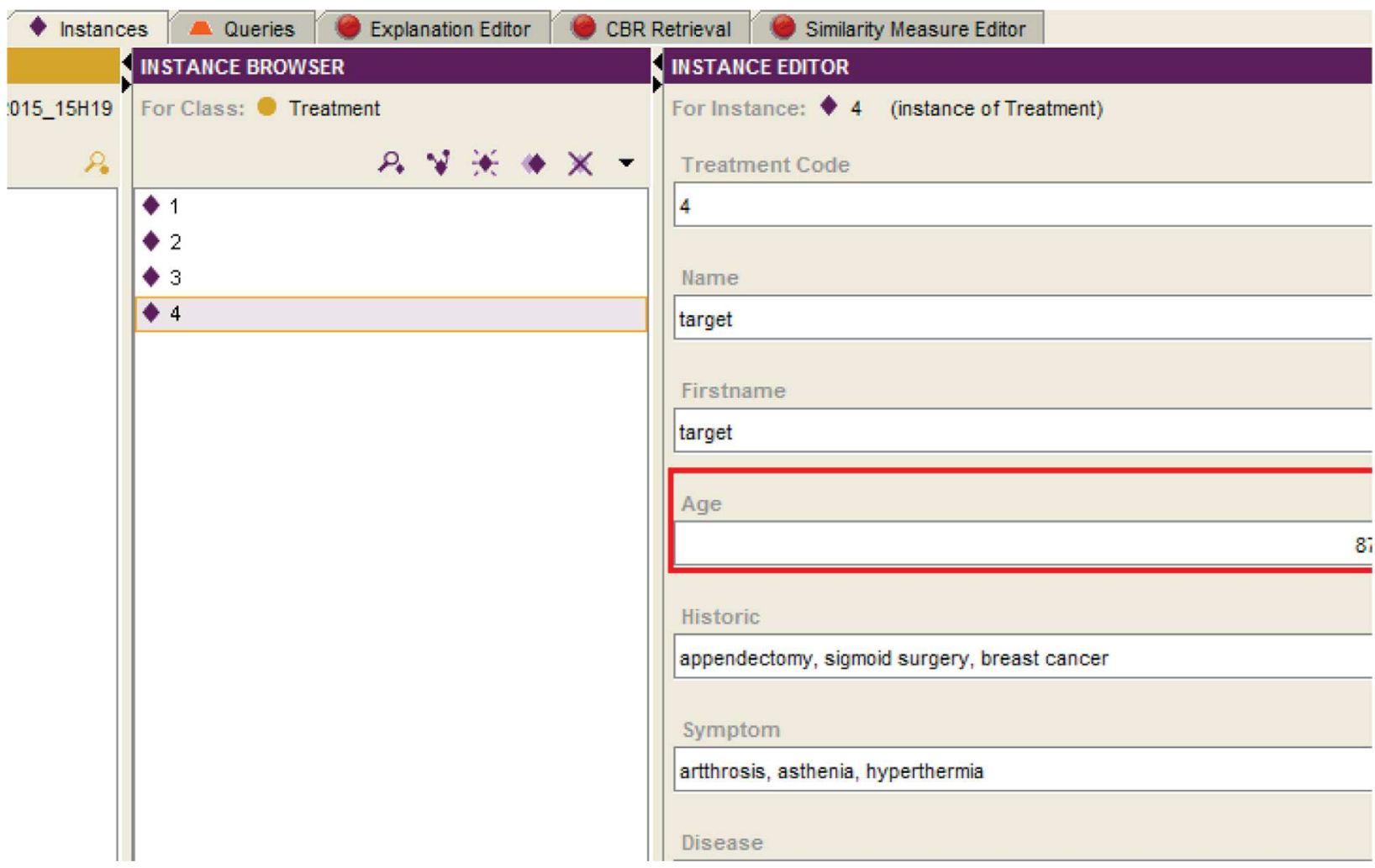

Fig. 19 - Case registration.

exclusion criteria. The difficulty is that a physician is caring for an individual with a degree of variation from the average. Moreover, some of the real patients would not have met the inclusion criteria or would have had to be excluded. Our method could provide a way to assess the positive or detrimental effects on those patients of the process while identifying the deviations and providing relevant hypotheses on an explanation of those effects.

\section{Conclusion}

This study proved the preliminary feasibility of a telemedicine framework using case based reasoning with evidences. This framework is complementary to the previous ones [21-35] in terms of evidences, considering the sensitivity and specificity of evidence-based practices. The technical architecture is proposed with an application of the conceptual method in the field of geriatric oncology.

This architecture with five-step process instead of four, points up particularly evidences and specialist's opinions for effectiveness and safety of the cares. Each step is performed using tools from knowledge engineering and information processing (e.g. data structuration, ontology modeling, and similarity measure).

On the basis of four real cases (three sources and one target), we have implemented each step of the case-based reasoning enriched with evidences. Even if the cases used are real, the functionality of this tool will be certified after the good general correlation between the results obtained and the expert's analysis. This will be done in further works.
In a medium-term perspective, we will also improve and automate each module of the proposed system, our aim being to build a framework accepted by all stakeholders (e.g. patient, medical professionals and healthcare authorities)

\section{Conflict of interest}

None declared.

\section{REFERENCES}

[1] M. Quirk, Intuition and Metacognition in Medical Education: Keys to Developing Expertise, Springer Publishing Company, Inc., New York, 2006.

[2] S. Montani, et al., Diabetic patients management exploiting case-based reasoning techniques, Comput. Methods Progr. Biomed. 62 (3) (2000) 205-218.

[3] P. Simon, W. Pellitteri, Le décret français de télémédecine: une garantie pour les médecins, Eur. Res. Telemed. 1 (2) (2012) 70-75.

[4] J.L. Kolodner, An introduction to case-based reasoning, Artif. Intell. Rev. 6 (1) (1992) 3-34.

[5] I. Watson, Case-based reasoning is a methodology not a technology, Knowl. Based Syst. 12 (1999) 303-308.

[6] M.B. Doumbouya, B. Kamsu-Foguem, H. Kenfack, C. Foguem, A framework for decision making on teleexpertise with traceability of the reasoning, IRBM 36 (1) (2014) 40-51.

[7] Lirmm. CoGui. http://www.lirmm.fr/cogui (last accessed on 10 May 2015).

[8] M. Singh, et al., Application of handheld tele-ECG for health care delivery in rural India, Int. J. Telemed. Appl. 2014 (2014), 
http://dx.doi.org/10.1155/2014/981806, Article ID 981806, 6 pages,

http://www.hindawi.com/journals/ijta/2014/981806/cta/

[9] GCS Télésanté Midi-Pyrénées.

https://www.telesante-midipyrenees.fr/portail/ (last accessed on 10 May 2015).

[10] A. Giorgio, A miniaturized medical device for health monitoring and teleassistance applications, Int. J. Bioinform. Res. 4 (1) (2012) 258-262.

[11] K. Dramé, G. Diallo, F. Delva, J.F. Dartigues, E. Mouillet, R. Salamon, F. Mougin, Reuse of termino-ontological resources and text corpora for building a multilingual domain ontology: an application to Alzheimer's disease, J. Biomed. Inf. 48 (2014) 171-182.

[12] T.R. Gruber, A translation approach to portable ontology specifications, Knowl. Acquis. 5 (2) (1993) 199-220.

[13] G. van Heijst, A.Th. Schreiber, B.J. Wielinga, Using explicit ontologies in KBS development, Int. J. Hum. Comput. Stud. 46 (2-3) (1997) 183-292.

[14] B. Tulu, S. Chatterjee, M. Maheshwari, Telemedicine taxonomy: a classification tool, Telemed. E-Health 13 (3) (2007) 349-358.

[15] Stanford University. Protégé. protege.stanford.edu (last accessed on 10 May 2015).

[16] P.A. Potes Ruiz, B. Kamsu-Foguem, D. Noyes, Knowledge reuse integrating the collaboration from experts in industrial maintenance management, Knowl. Based Syst. 50 (2013) 171-186.

[17] M. Ba, G. Diallo, Large-scale biomedical ontology matching with ServOMap, IRBM 34 (1) (2013) 56-59.

[18] B.A. Muellera, C. Obcemea, J. Lee, S. Sim, Pilot study of a radiation oncology telemedicine platform, Radiat. Oncol. Inf. 2 (1) (2010) 20-30.

[19] L.H. Sobin, M.K. Gospodarowicz, C. Wittekind (Eds.), TNM Classification of Malignant Tumors, Wiley-Blackwell, Oxford, 2009, ISBN 978-1-4443-3241-4.

[20] L.A. Winters-Miner, P.S. Bolding, J.M. Hilbe, M. Goldstein, T. Hill, R. Nisbet, N. Walton, G.D. Miner, Evidence-Based Medicine, in: Practical Predictive Analytics and Decisioning Systems for Medicine: Informatics Accuracy and Cost-Effectiveness for Healthcare Administration and Delivery Including Medical Research, Elsevier Inc., 2015, pp. 96-105 (Chapter 7)

[21] B. Kamsu-Foguem, P.F. Tiako, E. Mutafungwa, C. Foguem, Knowledge-based modelling applied to synucleinopathies, Eur. Geriatr. Med. (2015), http://dx.doi.org/10.1016/j.eurger.2015.02.011.

[22] B. Kamsu-Foguem, G. Tchuenté-Foguem, C. Foguem, Using conceptual graphs for clinical guidelines representation and knowledge visualization, Inform. Syst. Front. 16 (4) (2014) 571-589.

[23] B. Kamsu-Foguem, G. Tchuenté-Foguem, C. Foguem, Conceptual graph operations for formal visual reasoning in the medical domain, IRBM 35 (5) (2014) 262-270.

[24] B. Kamsu-Foguem, G. Tchuenté-Foguem, C. Foguem, Verifying a medical protocol with temporal graphs: the case of a nosocomial disease, J. Crit. Care 29 (4) (2014) 690.e1-690.e9.

[25] B. Kamsu-Foguem, C. Foguem, Adverse drug reactions in some African herbal medicine: literature review and stakeholders' interview, Integr. Med. Res. 3 (3) (2014) 126-132.

[26] B. Kamsu-Foguem, G. Diallo, C. Foguem, Conceptual graph-based knowledge representation for supporting reasoning in African Traditional Medicine, Eng. Appl. Artif. Intell. 26 (4) (2013) 1348-1365.

[27] K. Tafin-Kampé, B. Kamsu-Foguem, Acute osteomyelitis due to Staphylococcus aureus in children: what is the status of treatment today? Pediatr. Infect. Dis. 5 (3) (2013) 122-126.
[28] B. Kamsu-Foguem, G. Tchuenté-Foguem, L. Allart, Y. Zennir, C. Vilhelm, H. Mehdaoui, D. Zitouni, H. Hubert, M. Lemdani, P. Ravaux, User-centered visual analysis using a hybrid reasoning architecture for intensive care units, Decis. Support Syst. 54 (1) (2012) 496-509.

[29] B. Kamsu-Foguem, P.F. Tiako, L.P. Fotso, C. Foguem, Modeling for effective collaboration in telemedicine, Telemat. Inform. 32 (4) (2015) 776-786

[30] M.B. Doumbouya, B. Kamsu-Foguem, H. Kenfack, C. Foguem, Telemedicine using mobile telecommunication: towards syntactic interoperability in teleexpertise, Telemat. Inform. 31 (4) (2014) 648-659.

[31] B. Kamsu-Foguem, Systemic modeling in telemedicine, Eur. Res. Telemed. 3 (2) (2014) 57-65.

[32] B. Kamsu-Foguem, Ontological view in telemedicine, Eur. Res. Telemed. 3 (2) (2014) 67-76.

[33] B. Kamsu-Foguem, C. Foguem, Could telemedicine enhance traditional medicine practices? Eur. Res. Telemed. 3 (3) (2014) 117-123.

[34] B. Kamsu-Foguem, C. Foguem, Telemedicine and mobile health with integrative medicine in developing countries, Health Policy Technol. 3 (4) (2014) 264-271.

[35] G. Paré, M. Jaana, C. Sicotte, Systematic review of home telemonitoring for chronic diseases: the evidence base, J. Am. Med. Inform. Assoc. 14 (May-Jun (3)) (2007) 269-277.

Alsane Sene is a PhD student in the University of Toulouse and is registered at the Doctoral School of Aeronautics Astronautics (EDAA) associated to the ISAE-SUPAERO. His research area concerns information processing and knowledge modelling in health information technology with particular focus on the telemedicine. He holds a Master of Science in Computer Sciences and Telecommunications at the University of Toulouse and also earned a professional Master degree in embedded and real-time systems at the University of Toulouse. He has some skills and competencies in modeling and analysis for the development of software applications and embedded networks.

Bernard Kamsu Foguem is currently a tenured Associate Professor at the National Engineering School of Tarbes (ENIT) of National Polytechnic Institute of Toulouse (INPT) and undertakes research in the Production Engineering Laboratory (LGP) of ENIT-INPT, a research entity (EA1905) of the University of Toulouse. He is a visiting scholar in some renowned universities: United Kingdom (e.g. Oxford Brookes University, Oxford), Finland (e.g. Aalto University, Helsinki University of Technology, VTT Technical Research Centre of Tampere, University of Oulu, Åboakademi of Turku University). He is also involved in the thematic group: e-Health of InterOP-VLab (International Virtual Laboratory for Enterprise Interoperability). He is a member of International Editorial Reviewer Board of Artificial Intelligence Research and a reviewer for a large number of international scientific journals such as Knowledge-Based Systems, Engineering Applications of Artificial Intelligence, International Journal of Production Research, Journal of Intelligent Manufacturing, Computer Methods and Programs in Biomedicine, Computers in Biology and Medicine, Interacting with Computers, Sensors and Knowledge Management Research \& Practice. He got the "accreditation to supervise research", abbreviated HDR from University of Toulouse in 2013. He has a Master's in Operational Research, Combinatorics and Optimization (2000) from National Polytechnic Institute of Grenoble, and a PhD in Computer Science and Automation (2004) from the University of Montpellier 2. His current interests are in Knowledge Discovery and Data Mining, Knowledge Representation, Formal Visual Reasoning, Ontology-based Semantic Analysis, Knowledge Exploitation for remote Collaboration, Decision Support Systems and 
Intelligent Systems. The application range is extensive and includes Continuous Improvement Processes, Reliability centered Maintenance, Building Information Modeling and Health Information Systems.

Dr. Pierre Rumeau MD PhD is a consulting geriatrician at University Hospital Toulouse and is the head of $\mathrm{La}$ Grave Gerontechnology Laboratory, Gerontopole/UMR1027 Inserm-Toulouse University. $\mathrm{He}$ is a senior lecturer in risk management for the international master of mechatronic systems for rehabilitation (Paris6-Brescia). He has a PhD in Model, Methods and Algorythms in biology, health and environment (2010) from the University of Grenoble. He has been involved in several scientific projects relating to health, telemedicine, compensation and technology (e.g. AILISA, DOMEO, Healthware, Homecare, PréDICA, MIRAS, Monimad, RESATER, Riddle, TANDEM, UR-Safe). 